\title{
Hepatosplenic Schistosomiasis in Field-based Studies: a Combined Clinical and Sonographic Definition
}

\author{
José Roberto Lambertucci $/{ }^{+}$, Gláucia Fernandes Cota, Rogério Augusto \\ Pinto-Silva, José Carlos Serufo, Rogério Gerspacher-Lara, Sandra Costa \\ Drummond*, Carlos Maurício Antunes**, Vandack Nobre, Abdunnabi Rayes
}

\author{
Serviço de Doenças Infecciosas e Parasitárias, Departamento de Clínica Médica, Faculdade de Medicina, \\ Universidade Federal de Minas Gerais, Av. Alfredo Balena 190, 30130-100 Belo Horizonte, MG, Brasil \\ *Fundação Nacional de Saúde, Brasília, DF, Brasil **Departamento de Parasitologia, ICB/UFMG, \\ Belo Horizonte, MG, Brasil
}

A combined clinical and sonographic classification of hepatosplenic schistosomiasis mansoni to be used in field-based studies is proposed herein. Seven hundred forty one individuals out of 892 (83\%), living in an area endemic for schistosomiasis in Brazil, have been ubmitted to clinical and ultrasound examinations. Based on two stool examinations the overall prevalence for schistosomiasis in this area was $73 \%$. Abdominal palpation was performed with patients in dorsal decubit, during deep breath, by two experienced physicians and a portable ultrasound was used for the evaluation of liver fibrosis, portal collaterals and spleen size. Four groups of individuals were identified using data obtained by abdominal palpation and ultrasound examination: (1) palpable spleen and intense periportal thickening in 9 individuals (1.2\%); (2) spleen not palpable and intense periportal thickening in 15 (2\%); (3) palpable spleen with light to moderate periportal thickening in 32 (4.3\%), and (4) palpable spleen with a normal liver on ultrasound in 30 (4\%). The definition of hepatosplenic schistosomiasis in field-based studies as the finding of Schistosoma mansoni eggs in the stools in an individual with splenomegaly is not acceptable anymore. Abdominal ultrasound should be combined with clinical examination to accurately identify hepatosplenics in endemic areas for schistosomiasis.

Key words: schistosomiasis - ultrasound - hepatosplenomegaly - splenomegaly - morbidity

Hepatosplenic schistosomiasis is the best known form of the chronic disease and usually results from heavy Schistosoma mansoni infection. Genetic factors also seem to predispose certain individuals to developing hepatosplenic schistosomiasis (Abel \& Dessein 1991).

In most individuals with hepatosplenic schistosomiasis the spleen is increased in size. Splenomegaly results from chronic passive congestion and hyperplasia of the reticuloendothelial system. Symmers fibrosis, however, occurs without splenomegaly (Prata \& Andrade 1963). Even in hospitalized patients it can be difficult sometimes to separate schistosomiasis from other diseases that evolve with splenomegaly.

In field-based studies the hepatosplenics can be distinguished from others with hepatointestinal schistosomiasis basically by the presence of sple-

\footnotetext{
${ }^{+}$Corresponding author. E-mail: lamber@net.em.com.br Received 14 May 2001

Accepted 25 July 2001
}

nomegaly and this has been attempted by abdominal palpation. In the last two decades some works comparing splenic palpation to more accurate means for the diagnosis of splenomegaly (scintilography and ultrasound) have been published showing limitations of abdominal palpation (Barkun et al. 1991). More recently, Gerspacher-Lara et al. (1998), comparing physical examination with ultrasound, concluded that splenic palpation is a poor method for the diagnosis of splenomegaly in endemic areas for schistosomiasis.

Lately, the general availability of portable ultrasound makes it possible to improve the accuracy of clinical examination in areas located far from the big cities. In this paper, examining individuals of a hyperendemic area for schistosomiasis in Brazil, we have observed four groups of hepatosplenics and a combined clinical and sonographic classification of schistosomiasis is proposed herein to be used in field-based studies.

\section{MATERIALS AND METHODS}

Study area and patients - Queixadinha is a rural community in the northeast of the State of Minas Gerais, an area of high prevalence of schistosomiasis mansoni but where other tropical diseases that 
can cause splenomegaly, such as visceral leishmaniasis and malaria, have not been identified in the last two decades. A detailed description of the area can be found elsewhere (Lambertucci et al. 1996, Gerspacher-Lara et al. 1997).

The baseline characteristics of the studied population are depicted in the Table. There were 741 out of 892 (83\%) people submitted to physical examination and two stool examinations by the Kato-Katz technique. Ages ranged from 5 to 93 years (mean: 28; median: 22). The classification of skin color (white and non-white) was based on the subjective opinion of the examiner and alcohol abuse was defined as the ingestion of more than 60 $\mathrm{g}$ of alcohol per day ( $40 \mathrm{ml}$ of a local distilled sugarcane derived drink - "pinga", or two bottles of beer). Adults and children older than 5 years were also submitted to abdominal ultrasound. Informed consent was obtained for this study and it has been approved by the ethics committe of the Federal University of Minas Gerais. Children younger than 5 years were excluded of the study because of the difficulty in examining them with ultrasound and due to the absence in the literature of normal values for the parameters measured in this study.

The overall prevalence of $S$. mansoni infection in this area, based on two stool examinations, was 73\%. The highest prevalence was observed among

\section{TABLE}

Baseline characteristics and worm burden (eggs/gram of feces) of 741 individuals of an endemic area for schistosomiasis mansoni in the northeast of the State of Minas Gerais in Brazil, 1993-1997

\begin{tabular}{lcc}
\hline Characteristics & Number (\%) & $\begin{array}{c}\text { Eggs/gram } \\
\text { of feces }\end{array}$ \\
\hline $\begin{array}{ccc}\text { Age (years) } \\
5-9\end{array}$ & $90(12.2)$ & 213 \\
$10-19$ & $252(34)$ & 298 \\
$20-29$ & $97(13.1)$ & 203 \\
$30-39$ & $82(11.1)$ & 119 \\
$40-49$ & $86(11.6)$ & 71 \\
$50-59$ & $67(9)$ & 68 \\
$>60$ & $67(9)$ & 57 \\
Sex & & \\
Men & $359(48.4)$ & $152^{a}$ \\
Women & $382(51.6)$ & 218 \\
Skin color & & \\
White & $111(15)$ & $185^{a}$ \\
Non-white & $630(85)$ & 185 \\
Alcohol abuse & & \\
Yes & $160(22.2)$ & $209^{a}$ \\
No & $561(77.8)$ & 173 \\
\hline
\end{tabular}

$a$ : mean egg output was not statistically different for gender, skin color and alcohol abuse; $b$ : in 20 patients the information on alcohol abuse was not available. individuals aged 10 to 19 years (78\%) and mean egg output in this age group was 298/g of feces. There were 172 individuals living in houses which surrounded the building where the medical facilities were installed, who were submitted to six stool examinations. The prevalence of schistosomiasis increased from 58\% (2 stool samples) to $92 \%$ (with 6 samples), indicating that almost all the population was infected and that the negative results in parasitological examinations were probably falsenegatives; some of them should be chronic low egg excreters.

Abdominal palpation was performed with patients in dorsal decubit, during deep breath, by two experienced physicians. Spleen has been considered to be palpable when the splenic border was felt below the left costal margin by both examiners.

Sonography of the abdomen - Abdominal ultrasound was performed using real time equipment with electronic linear (Hitachi EUB 200) 3.5 MHz transducers. The splenic transverse diameter was recorded by an ultrasonographist who was unaware of the results of physical examination. Splenomegaly was considered to be present when splenic length was greater than $120 \mathrm{~mm}$ for individuals older than 17 years according to the definition proposed by the World Health Organization for adults living in Africa and Latin America (Hatz et al. 1992). For children aged 6 to 17 years, the upper normal splenic length $(\mathrm{mm})$ was calculated from the formula: $60+$ (age x 10)/3 (Teele \& Share 1991).

Peripheral fibrosis was considered to be present when three peripheral portal branches with thickened walls ( $>2 \mathrm{~mm}$ ) were described; thickening of the gallbladder wall (> $5 \mathrm{~mm}$ ) was also considered (Gerspacher-Lara et al. 1997). The presence of portosystemic collaterals were annotated (Domingues et al. 1993). In all cases the opinion of the ultrasonographist in regard to the presence of intense periportal thickening was also considered (Pinto-Silva et al. 1994).

Data analysis - Statistical tests (chi-square with Yates correction and fisher exact test) for comparisons of proportions were performed with the aid of EpiInfo version $6.04 \mathrm{~b}$ software. To evaluate the association of periportal thickening with age, linear regression was used. The statistical significance of results was tested at a 5\% level.

\section{RESULTS}

As the prevalence of schistosomiasis based on 6 stool examinations in a sample of 172 individuals randomly selected was as high as $92 \%$, we considered the whole population in this area infected with S. mansoni.

The discordance about the presence of a palpable spleen by two independent examiners was 
not significantly different $(\mathrm{p}=0.40)$. Splenomegaly was diagnosed by abdominal palpation in 71 out of 741 individuals examined (9.6\%). Four groups of individuals have been identified using data obtained by abdominal palpation and ultrasound examination (Figure): (1) palpable spleen and intense periportal thickening in 9 individuals $(1.2 \%)$; (2) spleen not palpable and intense periportal thickening in $15(2 \%)$; (3) palpable spleen with light to moderate periportal thickening in 32 (4.3\%), and (4) palpable spleen with a normal liver on ultrasound in $30(4 \%)$.

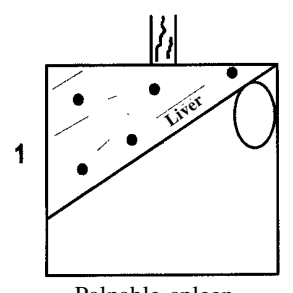

Palpable spleen

Intense periportal thickening Portal hypertension

3

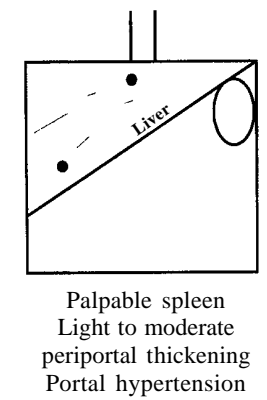

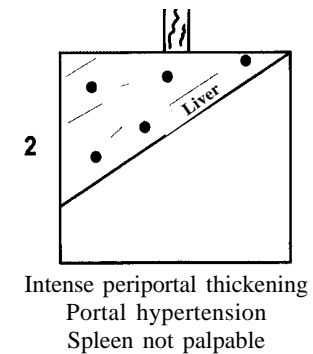

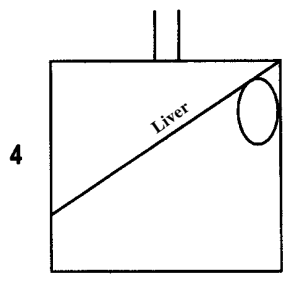

Palpable spleen
Four groups of individuals identified in an area endemic for schistosomiasis mansoni in Brazil using a combined clinical and sonographic classification.

The intensity of periportal thickening increased with age. The mean age in patients with intense periportal thickening was 38 years (groups 1 and 2) versus 23 years for the group 3 with light to moderate fibrosis $(\mathrm{p}=0.002)$, and 22 years for the group with normal liver on ultrasound (groups 1 and 2 versus group $4 ; \mathrm{p}=0.001$ ).

It was observed an increase in the peripheral portal vein wall thickness (second order vessel) with age; linear regression analysis showed that for each year of increase in age, thickening increased, in average, $0.009 \mathrm{~mm}$ (CI 0.006-0.013).

The prevalence of a palpable spleen increased with the grade of periportal thickening, increasing from $7.1 \%$ in individuals with normal liver on ultrasound to $37.5 \%$ in patients with intense periportal thickening $(p=0.000002)$. Fifty eight percent of the patients with splenomegaly had some degree of periportal thickening.

\section{DISCUSSION}

What means a palpable spleen in a subject living in an endemic area for schistosomiasis mansoni and who is also passing eggs of S. mansoni in the stools? Untill very recently it meant that this individual had hepatosplenic schistosomiasis, also considered or called by some authors, the severe form of the disease (Kloetzel 1962). Based on this concept a series of investigations of prevalence, and correlations with age, gender, skin color, worm burden, different aspects of morbidity before and after treatment, and a series of immunological studies have been developed and reported (Lambertucci 1993).

With the advent of new techniques such as ultrasonography, computed tomography, echodopplercardiography and magnetic resonance imaging a new perspective has been introduced in our approach to most diseases and a better understanding of morbidity in schistosomiasis (Barbosa et al. 1996). The development of serological and biochemistry tests for the diagnosis of other diseases like hepatitis B and C, mononucleosis-like syndromes, leishmaniasis, hemoglobinopathies, among others have also facilitated the identification of the association of diseases and the separation of one from the other (Aggio 1990).

The definition of hepatosplenic schistosomiasis in field-based studies as the finding of $S$. mansoni eggs in the stools of an individual with clinical diagnosed hepatosplenomegaly (with or without any particular characteristic of the liver) is not acceptable anymore (Lambertucci et al. 2000).

In the present study, ultrasound identified 15 individuals among 741 examined (2\%) who had intense periportal thickening and the spleen was not palpable. This means that these patients with severe schistosomiasis have not been included in previous studies of morbidity in field-based studies on schistosomiasis. A similar observation has been made before in Sudan (Homeida et al. 1988). The development of spontaneous shunts may well explain some cases of portal hypertension without an enlarged spleen.

Nine subjects out of 741 (1.2\%) presented intense periportal thickening on ultrasound and a palpable spleen and it is reasonable to sustain that this is the classical group of individuals called hepatosplenics and more often seen in the wards of reference city hospitals because of variceal bleeding.

In another group of 32 individuals, representing $4.3 \%$ of the population studied, the spleen was palpable but there was only light to moderate periportal thickening on ultrasound examination. No signs of portal hypertension were present in this 
group. We suspect that splenomegaly in this group is explained in great part by schistosomiasis and would represent the reactive hyperplastic stage of the disease. Given enough time the disease may accordingly evolve into the severe form of schistosomiasis. It is also tempting to identify this group as the one which presents involution of the spleen after successful treatment with schistosomicides as shown by others (Bina \& Prata 1983).

The existence of a fourth group of individuals with splenomegaly and a normal liver on ultrasound $(30 / 741 ; 4 \%)$ is interesting and open to considerations. This group may also present a reactive splenomegaly due to $S$. mansoni infection or else the splenomegaly is caused by other diseases not investigated in the present study.

Our present observation should open a series of possibilities for future investigations. Each group identified in our study should be examined further. Particularly, the splenomegaly of individuals in groups 3 and 4 are in need of more exploration. Do they have esophageal varices that were not seen by ultrasound? What is their immunological profile? Other diseases that may evolve with splenomegaly will have to be investigated in this group of individuals. Our research group is trying to address and respond each and every one of these questions.

\section{REFERENCES}

Aggio MC 1990. Dacie's syndrome and other splenomegalies of unknown origin. Rev Invest Clin 42: 142144.

Abel L, Dessein A 1991. Genetic predisposition to high infections in an endemic area for schistosomiasis mansoni. Rev Soc Bras Med Trop 24: 1-3.

Barbosa MM, Lamounier JA, Oliveira EC, Souza MV, Marques DS, Silva AA, Lambertucci JR 1996. Pulmonary hypertension in schistosomiasis mansoni. Trans R Soc Trop Med Hyg 90: 663-665.

Barkun AN, Camus M, Green L, Meagher T, Coupal L, De Stempel J, Grover SA 1991. The bedside assessment of splenic enlargement. Am J Trop Med 91: 512-518.

Bina JC, Prata A 1983. Regressão da hepatoesplenomegalia pelo tratamento específico da esquistos- somose. Rev Soc Bras Med Trop 16: 213-218.

Domingues AL, Lima AR, Dias HS, Leao GC, Coutinho A 1993. An ultrasonographic study of liver fibrosis in patients infected with Schistosoma mansoni in the northeast of Brazil. Trans R Soc Trop Med Hyg 87: 555-558.

Gerspacher-Lara R, Pinto-Silva RA, Rayes AAM, Drummond SC, Lambertucci JR 1997. Ultrasonography of periportal fibrosis in schistosomiasis mansoni in Brazil. Trans R Soc Trop Med Hyg 91: 307-309.

Gerspacher-Lara R, Pinto-Silva RA, Serufo JC, Rayes AAM, Drummond SC, Lambertucci JR 1998. Splenic palpation for the evaluation of morbidity due to schistosomiasis mansoni. Mem Inst Oswaldo Cruz 93: 67-71.

Hatz C, Jenkins JM, Morrow RH, Tamer M 1992. Ultrasound in schistosomiasis. A critical look at methodological issues and potential applications. Acta Trop 51: 89-97.

Homeida M, Ahmed S, DaFalla A, Suliman S, Eltom I, Nash T, Bennett JL 1988. Morbidity associated with Schistosoma mansoni infection as determined by ultrasound: a study in Gezira, Sudan. Am J Trop Med 39: 196-201.

Kloetzel K 1962. Splenomegaly in schistosomiasis mansoni. Am J Trop Med 11: 472-476.

Lambertucci JR 1993. Schistosoma mansoni: pathological and clinical aspects. In P Jordan, G Webbe, RF Sturrock (eds), Human Schistosomiasis, Cab International, Wallingford. p. 195-225.

Lambertucci JR, Gerspacher-Lara R, Pinto-Silva RA, Barbosa MM, Teixeira R, Barbosa HF, Serufo JC, Rezende DF, Drummond SC, Rayes AAM 1996. O projeto Queixadinha: a morbidade e o controle da esquistossomose em área endêmica no nordeste de Minas Gerais, Brasil. Rev Soc Bras Med Trop 29: 127-135.

Lambertucci JR, Serufo JC, Gerspacher-Lara R, Rayes AAM, Teixeira R, Nobre V, Antunes CMF 2000. Schistosoma mansoni: assessment of morbidity before and after control. Acta Trop 77: 101-109.

Pinto-Silva RA, Abrantes WL, Antunes CMF, Lambertucci JR 1994. Sonographic features of portal hypertension in schistosomiasis mansoni. Rev Inst Med Trop São Paulo 36: 355-361.

Prata A, Andrade Z 1963. Fibrose hepática sem esplenomegalia. Hospital 63: 617-623.

Teele RL, Share JC 1991. Ultrasonography of Infants and Children, WB Saunders, Philadelphia, $235 \mathrm{pp}$. 